\title{
The quantitative evaluation method of technology management in medium-sized manufacturing companies
}

\author{
[Hiroki NAKAMURA, Koki SHIOHATA and Hideki KAWAMURA]
}

\begin{abstract}
As management resources of the company, generally "people", "goods", "money (capital)" has been called that three elements of the management. Further "information" as a fourth element has been added recently. In this paper, furthermore, for the medium-sized manufacturing company that manufactures and sells the product with long life as mechanical elements, "outward activities" are proposed as the fifth element. The importance of these five management elements is different by market needs and corporate scale and strategy. So, the key method to evaluate importance of the management of technology is discussed systematically for mid-sized manufacturing company's management on the basis of these management elements. In the management of technology system are classified into three layers, and the evaluation factors based on the management elements in each layer are composed by a tree structure. In this case study, it's also done clearly about how various innovations is classified by management of technology system.
\end{abstract}

\section{Keywords - management of technology, outward activities, five management elements, tree structure, technical management table, evaluation score rate}

\section{Introduction}

For small businesses and midsize companies are working on the production development of products that are limited, high technology is required. [1][15][16] For this reason, the management is required advanced management of technology to promote the product development based on innovative technology and attractive product for the customer.[13] The task of management of technology is to acquire the accurate information and evaluate it systematically in the management and provide products quickly and in a timely manner (Tanimizu others, 2002)

\section{Hiroki Nakamura}

Graduate School of Science and Engineering, Ibaraki University, Nakamura Jico Co., Ltd.

Japan

\section{Koki Shiohata}

Graduate School of Science and Engineering, Ibaraki University, Japan

\section{Hideki Kawamura}

Nakamura Jico Co., Ltd.

Japan
In order to cope with characteristic shortening of the life cycle of a product in the current global society, each process of the execution management research on product development (Miwa, Aoyama, 2012) and design method which is mainly the product life cycle study (Nakagami, other, 2008), etc., after 2000, research and education on technology management (Japan Society of Mechanical Engineers, 2005) (Mori, 2008) has been reported the implementation. However, upon technology management implementation of the manufacturing companies, codified the skills and strategic thinking are called to remain implicit knowledge.

One of the authors runs a manufacturing medium-sized company and developing products of machine elements that business potential in a niche market. In this paper, the management of technology in mid manufacturing company with hierarchical management element, it is proposed a quantitative evaluation method, and intended to clarify the effectiveness based on the case.

In this paper, the conventional management three elements, "People", "Goods", "Money (capital)", in addition to "Information ", which can respond to information society and global society, "Outward activities" are proposed as management five elements.[2][3][4] Then, there is provided an evaluation item for each hierarchy, formulate the items that affect the management 5 elements that are the foundation of management of technology, it is relatively evaluated. This result revealed the effectiveness of the technology management method which was run five elements.

\section{Management Element}

A. Analysis of the Management three elements and five elements

Management elements described in the previous are analyzed for conventional three-elements and the five elements of the proposal.[10][11] As the data to be analyzed, it is chosen the "management policies and Code of Conduct" and "management philosophy" of the company as operational situation capable guesses. The latter does not change frequently, but the former is believed to vary by social conditions (Ogawa et al., 1989)[12]. Target companies are elected the Manufacturing leading 54 companies of the Tokyo Stock Market. .

Figure 1-4 in a pie chart (\%) shows the results of analysis by the management three elements, and by the management five elements. In this analysis, it shows how much each element in the "management philosophy" and "management policies and Code of Conduct" of each company is expressed. Therefore, the higher the number, it 
can be seen that the company has been focused on the element. From management 3 element analysis results, the evaluation of the "management philosophy" has been

in the order of "Goods" $\rightarrow$ "Money (Capital)" $\rightarrow$ "People", it can be seen that the "Goods" "Money(Capital)" has been emphasized. In the evaluation of the "management policies and Code of Conduct", "Money (Capital)" $\rightarrow$ "Goods" $\rightarrow$ "People", has become the order, particularly it is a feature of the evaluation of "Money (Capital)" is large.

On the other hand, from management 5 element analysis result of, in the "management philosophy", it is understood that the fifth element "outward activities" is next to the big importance of the "Goods". Also, unlike the management three elements, a decrease in the evaluation of "Money (Capital)" is characteristic. The cause of this reduction is to be distributed to the "Information", "Outward activities". In the evaluation of the "management policy and Code of Conduct ", it is understood that "Outward activities" is the largest and the most important compared with the other evaluation. For "Information", the evaluation is not so large, but it is believed estimated that there is a need. In addition, it has also become larger proportion of "Money (Capital)". It guesses "management policy and Code of Conduct" is that demand a realistic response. Therefore, for the three elements and five elements of management, the results of the analysis based on the data of the "management philosophy" and "management policies and Code of Conduct"., It becomes clear that the evaluation of "outward activities" of this proposal is important.[3] (Ito, 1997). Evaluation is lower for the "information", which is probably because of the inevitable requirement in recent IT age. In addition, evaluation of the "People", it is also a characteristic that is almost unchanged in the three elements and five elements. This is believed to be why it is referred to as the "Companies are its people."
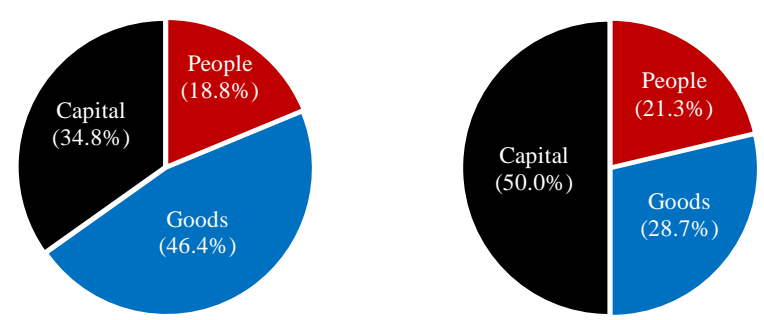

Figure 2. Percentage of management Figure 3. Percentage of management three elements of "management philosophy "

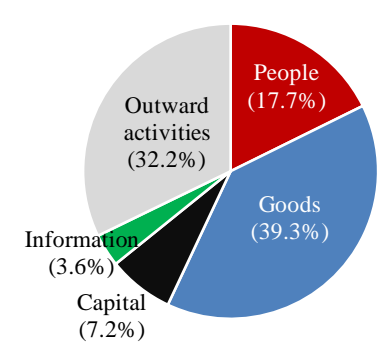
three elements of "management policy and action guideline"

Figure 4. percentage of management Figure 5. Percentage of management five elements of "management philosophy"

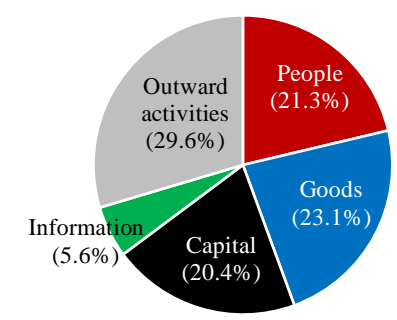
five elements of "management policy and action guideline"

\section{Management of Technology}

Management of Technology (MOT) is intended that the manufacturing industry is structured from the standpoint of business administration the accumulated know-how and concepts in the course of manufacturing.[5]

Therefore, it is in business administration for organizations that produce something using technology. Its purpose is to be determined and executed, which companies and organizations that do business while incorporating the new technology, for sustainable development, while performing the overall business management, including technology, - develop a strategy for going to create economic value.[6][7][8][9]

\section{a. Relation with 5 elements of management}

Management has a big influence on itself for technological management in a manufacturing enterprise. In particular, a medium sized manufacturing enterprise is management itself a core of the company. A relation about each element was strong in a relation between an element of management and technological management. However, to need a judgment including a relation between the elements as well as each element independence at present, it has become difficult that think with the technological management judged by element independence like the past. Therefore a proprietor has needed the systematized technological management which estimates each element overall.[14][15]

Five elements of management is classified as the management field, its evaluation percentage is written and it's shown. "People" focus on educating and developing of human resources, "Goods" is research and developing, "Money(Capital)" is management and benefits, and "Outward activities" emphasizes an behavior to customer. It can be judged quantitatively which field to put emphasis on in "management philosophy" and "management policy and Code of Conduct ".

\section{A. Systematization of technological management}

In this section, in order to perform this technological management, it sets the item by layering five elements of this proposal. The item is quantitatively evaluated, and describes a method that can judge systematic management decisions comprehensively to the entire each element

First, the five elements is a first layer, then the basic and important role factor a second tier for each element of the first layer, further the problems faced by the factor of the second layer a third layer, and finally specific factors to evaluate the management to be a fourth level. In Figure 6, first, to be quantified by setting the evaluation items to be executed as specifically required in the fourth layer, it will continue to shift to sequential quantitative assessment of the upper layer items. These quantitative evaluations of each level of the item are possible to overall judgment of corporate evaluation, in helping to promote the management of technology. A Table summarizing all of these hierarchies is called the management of technology data table (TMD) sheet. It schematically shows the configuration in Figure 7. In this paper, management of technology to run on the basis of this TMD sheet is called a Management of Technology Management System (MOTMS). Figure 7 shows the flow of technology management using this MOTMS. 
In addition, it can be determined importance of management of technology compared with the reference value. This now can determine whether or not, the financial health aimed or measures against the challenges that faced the company are sufficient.

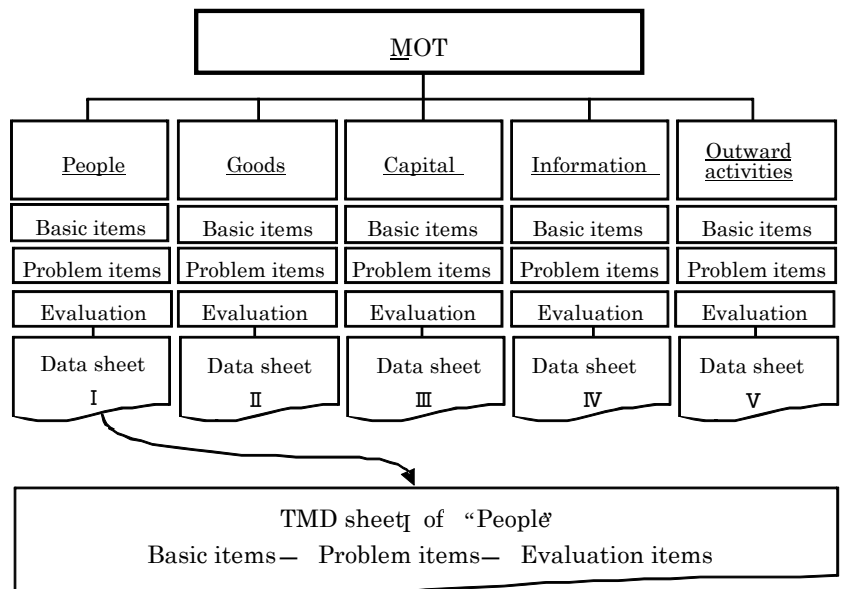

Figure 6. Structure of MOT. TMD sheets are divided as four layers.

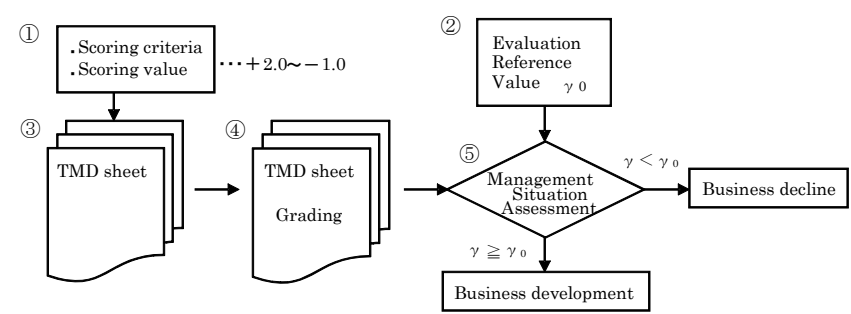

Figure 7. Performance evaluation of manufacturing companies by MOTMS After each items on TMD sheets makes evaluation score $\gamma_{(1,2,3)}$, $\gamma_{0}$ is as threshold of evaluating business environment.

\section{Iv. Management of Technology Management System (MOTMS)}

Management of Technology Management System (MOTMS) based on the TMD sheet, the management side is objective and quantitative evaluate the current state of the design and manufacturing technology for the product, it is created technical management system to find the improvements required and their relationships for management. Below is to create a technical management data (TMD) sheet to quantify the evaluation value for the configuration factor of each hierarchy that created in Chapter III.

Figure 7 shows a schematic flow of technical management of the manufacturing companies those based on TMD sheet, the procedure as follows

\section{A. fourth layer evaluation method}

(1) To create a configuration factor of each hierarchy.

(2) To enter three stages of evaluation value $(1,0.5,0)$, to the evaluation items of the fourth layer

(3) To make modifications to the evaluation value. It adds +0.5 if it affects the third layer and further +0.5 added if it also affects the second layer. This is intended to give weight to the item of outcomes.
(4) To enter the evaluation reference value $\gamma 0$ to evaluate the relative merits of the evaluation score rate.

(5) To obtain the evaluation score ratio $\gamma$ in the order of the third layer, the second layer, the first layer based on the evaluation value of the fourth layer determined in (3) .

(6) To make a comparison between the evaluation reference value $\gamma 0$ determined in advance to $\gamma(3), \gamma(2)$, with $\gamma(1)$ obtained (5). It can also be a comparison between the average value and the criterion value of the items belonging to each layer, as the evaluation score index of the second and third layer,

(7) In case of the evaluation score rate $\gamma$ is smaller than evaluation reference value $\gamma 0$, it is determined whether or not to be improved or intentional.

\section{B. third layer evaluation method}

To introduce the following points ratio in order to obtain the evaluation scores of the first to third layers.

P: score of the fourth layer,

$\mathrm{i}$ : the first layer item number $(\mathrm{i}=1,2, \cdots, \mathrm{I})$

$\mathrm{j}$ : second layer item number $(\mathrm{j}=1,2, \cdots, \mathrm{J})$

$\mathrm{k}$ : the third layer item number $(\mathrm{k}=1,2, \cdots, \mathrm{K})$

l: fourth layer item number $(1=1,2, \cdots, \mathrm{L})$

$\mathrm{N}(\mathrm{i}, \mathrm{j}, \mathrm{k})$ : belonging to the first layer $\mathrm{i}$, belong to the second layer $\mathrm{j}$,

the number of items of the fourth layer belonging to the third layer $\mathrm{k}$

$\mathrm{N}(\mathrm{i}, \mathrm{j})$ : belonging to the first layer $\mathrm{i}$, the number of items of the third layer belonging to the second layer $\mathrm{j}$

$\mathrm{N}$ (i): The number of items of the second layer belonging to the first layer i

Evaluation score rate of the items included in the first to third layers by using these criteria are obtained by the following equation.

(1) Evaluation score of the third layer

$$
\gamma_{a}^{(k)}=\gamma(i, j, k)=\frac{\sum_{l=1}^{\mathbb{N}(i, j, k)} P(i, j, k, l)}{N(i, j, k)}
$$

(2) Evaluation score of the second layer

$$
\gamma_{2}^{\mathbb{0}}=\gamma(i, j)=\frac{\sum_{k=1}^{K} \sum_{l=1}^{W(i, j, k)} P(i, j, k, l)}{\sum_{k=1}^{K} N(i, j, k)}
$$

(3) Evaluation score of the first layer

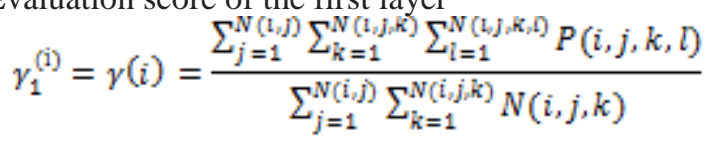

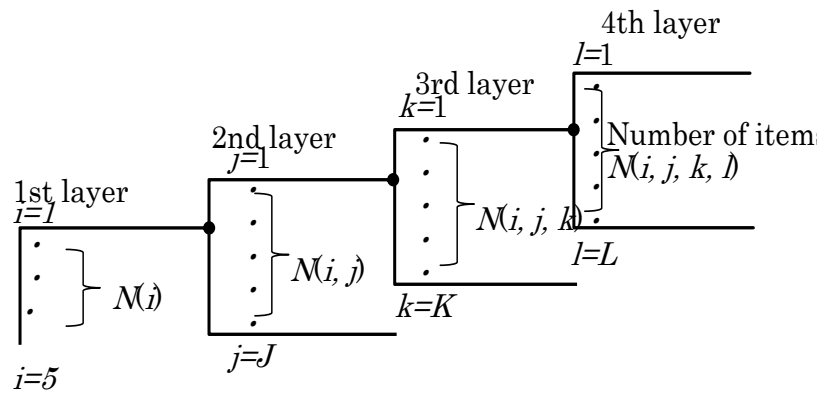

Figure 8. Symbol description of each of the layers 
Proc. of The Third Intl. Conf. on Advances in Social Science, Management and Human Behaviour - SMHB 2015

Copyright ( ) Institute of Research Engineers and Doctors, USA .All rights reserved.

ISBN: 978-1-63248-067-5 doi: 10.15224/ 978-1-63248-067-5-72

\section{Valuation method for obtaining the reference value $\gamma 0$}

It will be determined by the management's decision. For example, it is determined on the basis of each layer of the element average value and past the TMD sheet. Here is a $\gamma 0<1$.

It has also shown a flow of a reference value $\gamma 0$ in Figure 6. It should be noted, $\gamma 0$ for management element may be selected separately in common with the reference value of the lower of basic items and issues item. If the evaluation score rate $\gamma$ of more evaluation reference value for each layer is calculated, it can determine business and commercial content related to the item to be good. In the cases the evaluation reference value are below average, and if not performed deliberately, it is necessary to determine whether to be improved in the future. Thus, by a quantitative evaluation by creating a TMD sheet, overall judgment of management status of the company is possible in comparison with the evaluation reference value which has been predetermined.

\section{TMD example of the configuration of the sheet}

As discussed in Chapter III, for manufacturing technology management, the creation of TMD sheet plays an important role. In this feature, because of four hierarchies, management can evaluate each hierarchical management situation, furthermore for each item, and also can be evaluated as a whole.

\section{Case study of Company A}

This chapter verifies effectiveness of five elements of technology management, and effectiveness of systemization of technology management mentioned in the previous chapters.

Table 9 Evaluated goal average of "Information" $\left(\gamma_{2}\right)$

\begin{tabular}{c|c|c}
\hline \hline Globalization & Innovation & $\begin{array}{c}\text { Information } \\
\text { management }\end{array}$ \\
\hline 0.92 & 0.80 & 0.93 \\
\hline
\end{tabular}

Table 10 Evaluated goal average of "Outward activities" $\left(\gamma_{2}\right)$

Technical proposal 0.94

\begin{tabular}{|c|c|}
\hline & Customer satisfaction \\
\hline
\end{tabular}

\section{A. History and Business of company A}

Company A has been founded in 1929, currently selling parts of railway vehicle as the trading business, and manufacturing the universal joint shaft and the heat exchanger as manufacturer. The large universal joint shaft of Company A for steel's facilities are as a main product. This product is a universal joint shaft which is used in the roll driving the roughing rolling mill arranged on the preceding stage of the hot rolling line. Company $\mathrm{A}$ is manufacturing and selling every joint from $50 \mathrm{~mm}$ diameter to over $12 \mathrm{MN} / \mathrm{m}$ torque. Company A was certified ISO9001 "quality management system certification" of company-wide unified in 1999.

\section{B. TMD sheet analysis}

The contents of the TMD sheet of Company A are analyzed. The result in table 11 is analyzed based on a TMD sheet of Company A. The number of the items of the second layer in a table, the third layer is set beforehand. The number of the items of the low-ranking layer generally increases. The element averages in the bottom line denote each layer average in management five elements. The item averages denote each layer of management five elements. The evaluation standard values are defined by each layers average. Layer 1 is $0.874,2$ is $0.878,3$ is 0.86 in Table 8 . Each layer's standard value of deflection against evaluation standard value are defined by next formula.

The elements of deflection which exceed the standard value are "Capital/money", "Information", "Outward activities". These three elements are regarded as important. This shows that five elements which include "Information" and "Outward activities" are effective management of technology management system with manufacturing middle size company. On other front, "People" and "Goods" are under standard value. But both deflections are under 7\%., so that effectiveness is small and assumed well balance management of technology management system.

All items show the highest evaluation goal average more than the standard value. Table 9 has evaluation goal average belonging to "Outward activities", table 10 has evaluation goal average belonging to "Outward activities". Globalization and information management seemed important by "Information" from table 9. In table 10, it can be said that "Outward activities" has high evaluation average; especially technical proposal for customer is well operated.

Table 8 Analysis results of the evaluation score rate

\begin{tabular}{c|c|c|c|c|c|c|c|c}
\hline \hline & \multicolumn{2}{|c|}{ First layer } & \multicolumn{3}{c|}{ Second layer } & \multicolumn{3}{c}{ Third layer } \\
\cline { 2 - 9 } & $\begin{array}{c}\text { Evaluatio } \\
\text { n score } \\
\text { rate }\end{array}$ & $\begin{array}{c}\text { Deviation } \\
\text { rate }\end{array}$ & $\begin{array}{c}\text { Evaluatio } \\
\text { n score } \\
\text { rate }\end{array}$ & $\begin{array}{c}\text { Deviation } \\
\text { rate }\end{array}$ & $\begin{array}{c}\text { Number } \\
\text { of items }\end{array}$ & $\begin{array}{c}\text { Evaluatio } \\
\text { n score } \\
\text { rate }\end{array}$ & $\begin{array}{c}\text { Deviation } \\
\text { rate }\end{array}$ & $\begin{array}{c}\text { Number } \\
\text { of items }\end{array}$ \\
\hline People & 0.85 & -0.027 & 0.868 & -0.012 & 4 & 0.803 & -0.066 & 22 \\
\hline Goods & 0.82 & -0.062 & 0.819 & -0.068 & 7 & 0.825 & -0.041 & 38 \\
\hline Capital & 0.91 & 0.041 & 0.926 & 0.054 & 5 & 0.936 & 0.088 & 35 \\
\hline Information & 0.89 & 0.018 & 0.882 & 0.004 & 3 & 0.872 & 0.014 & 13 \\
\hline Outward activities & 0.90 & 0.030 & 0.898 & 0.022 & 2 & 0.865 & 0.005 & 12 \\
\hline Average value & 0.874 & & 0.878 & & & 0.860 & & \\
\hline
\end{tabular}


Table 11 Evaluate average ratio $\gamma_{(1,2,3)}$ to $\gamma_{(2,3)}(\%)$

\begin{tabular}{|c|c|c|c|c|c|c|c|}
\hline & $\gamma_{1}$ & & $\gamma_{2}^{*}$ & & & $\gamma_{3}^{*}$ & \\
\hline & - & $\begin{array}{c}\text { Under } \\
0.7\end{array}$ & $\underset{0.9}{\stackrel{0.7}{\sim}}$ & $\begin{array}{c}\text { Over } \\
0.9\end{array}$ & $\begin{array}{c}\text { Under } \\
0.7\end{array}$ & $\underset{0.9}{\stackrel{0.7}{\sim}}$ & $\begin{array}{c}\text { Over } \\
0.9\end{array}$ \\
\hline \multirow{2}{*}{ People } & \multirow{2}{*}{0.85} & 0 & 50 & 50 & 32 & 9 & 59 \\
\hline & & \multicolumn{3}{|c|}{4} & \multicolumn{3}{|c|}{22} \\
\hline \multirow{2}{*}{ Goods } & \multirow{2}{*}{0.82} & 14 & 43 & 43 & 29 & 21 & 50 \\
\hline & & \multicolumn{3}{|c|}{7} & \multicolumn{3}{|c|}{38} \\
\hline \multirow{2}{*}{ Capital/Money } & \multirow{2}{*}{0.91} & 0 & 20 & 80 & 9 & 14 & 77 \\
\hline & & \multicolumn{3}{|c|}{5} & \multicolumn{3}{|c|}{35} \\
\hline \multirow{2}{*}{ Information } & \multirow{2}{*}{0.89} & 0 & 33 & 67 & 23 & 8 & 69 \\
\hline & & \multicolumn{3}{|c|}{3} & \multicolumn{3}{|c|}{13} \\
\hline \multirow{2}{*}{$\begin{array}{l}\text { Outward } \\
\text { activities }\end{array}$} & \multirow{2}{*}{0.90} & 0 & 50 & 50 & 25 & 8 & 67 \\
\hline & & \multicolumn{3}{|c|}{2} & \multicolumn{3}{|c|}{12} \\
\hline
\end{tabular}

* : Above Percentage of $\gamma_{(2,3)}$, Bottom: numbers of evaluate items

\section{Conclusion}

Technical management system of the manufacturing medium-ranking enterprise has following conclusion.

1. Proposing management five elements which adding "Information" and "Outward activity" to existing management three elements "Capital/Money", "Goods" and "People". This management five elements lead technical management table which has four layers three construction.

2. Management three elements and management five elements analyze 54 Tokyo Stock Exchange listed companies on the view of "management philosophy" and "Code of Conduct". Importance of "Outward activities" includes and effectiveness of management five elements are verified.

3. Four layers of the technical management table of management five elements are defined as layer 1 are management, layer 2 are basic elements, layer 3 are problem items, layer 4 are evaluation items.

4. Proposing technique to quantify each item of the technical management table.

5. Thus, systematization of the technical management could carry out.

Proposed technical management system apply to the manufacturing medium company of the universal joint and conclude following.

1. It was revealed that "Outward activity" is an important point from the first layer.

2. It carried out innovation from the second layer, and especially process innovation get recognition.

3. Above 1 and 2 revealed features of manufacturing medium-ranking company of the machine element.

4. From a technical management table, a characteristic of the present conditions management and future management can judge the contents which they should reflect.

Thus, it is able to clarify the effectiveness of the management of technologyl system of this suggestion. To increase the number of the examples more will clarify coverage in future.

\section{References}

[1] Hoko, T., Ninomiya, K., Hoi, Y. and Hurukawa, I., Management thinking progress method for engineers, Nikkan kogyo Shimbun Ltd., (2011), pp.21-24 (in Japanese).

[2] Ito, K., Global management of Japan Company - Basic issues and commitment to the globalization of overseas production, Production management journal, Vol.4, No.2 (1997), pp.89-92 (in Japanese).

[3] Ito, K., International product management - Fundamentals of foreign production and action for globalization, Production management journal, Vol.4, No.1 (1997), pp.1-6 (in Japanese).

[4] Ito, K., Firm Activity in Market Economy, "QCD+NS" As Customer Evaluation Item (in Japanese), Production Management journal, Vol.3, No.2 (1996), pp.168-175 (in Japanese).

[5] Ministry of Economy, Trade and Industry, Recommendation for technology management from requirements of technology management program, $\lceil$ MOT $\rfloor$, for new human resource development by collaboration with industries and universities, (2005) (in Japanese).

[6] Ministry of Economy, Trade and Industry, Ministry of Economy, Trade and Industry business activities basic research - statistical tables list (time-series data), pp.44 (in Japanese).

[7] http://www.meti.go.jp/statistics/tyo/kikatu/result-2.html, (accessed on 25 May 2015) (in Japanese).

[8] Miwa, T. and Aoyama, H, Evaluation method of product development process with the development risk with the product value flow analysis, Transactions of the Japan Socienty of Mechanical Engineers, Series C, Vol.78, No.785 (2012), pp.312-326 (in Japanese).

[9] Mori, K, People in management of technology, Journal of the Japan Society of Mechanical Engineers, Vol.111, No.1072 (2008), pp.203206 (in Japanese).

[10] Murakami, T., Marketing strategy of Kotler, Gendai bijimesu heihou kennkyuukai, (2012), pp.78-89 (in Japanese),

[11] Nishimura, R., Kobayashi, N. and Akiyama,Y., beginning business management, Chuokeizai-sha, Inc., (2001), (in Japanese).

[12] Ogawa, E., Kitano, T., Goto, K., Takayanagi, A., Takayanagi, A. and Murata, A., Basic knowledge of Management, Yuhikaku Publishing Co., Ltd., (1989), pp.45 (in Japanese).

[13] Shomoto, J., Strength of Samsun electronics, Journal of Japan Society for Production Management, Vol.13, No.1 (2006), pp.111-116 (in Japanese).

[14] Tanimizu. Y., Nagata, T., Sugimura, N., Mitsuyuki, K., Yura, Y. and Tokunaga, N, A study on the design process support of the production system, , Transactions of the Japan Socienty of Mechanical Engineers, Series C, Vol.68, No.671 (2002), pp.312-326 (in Japanese).

[15] Peter F Drucker, Management and the World's Work, Harvard Business Review, 66, september 1988 P76

[16] Hermann Simon, Hidden Champions of the $21^{\text {st }}$ Century: success strategies of unknown world market leaders, 2012, p31

About Author (s)

[Type a quote from the document or the summary of an interesting point. You can position the text box anywhere in the document. Use the Drawing Tools tab to change the formatting of the pull quote Image text box.] 